
\title{
Aerial multispectral imaging for crop hail damage assessment in potato
}

\author{
Jianfeng Zhou ${ }^{1}$, Mark J. Pavek ${ }^{2}$, Seth C. Shelton ${ }^{2}$, Zachary J. Holden ${ }^{2}$, Sindhuja Sankaran ${ }^{1}$ * \\ ${ }^{1}$ Department of Biological Systems Engineering, Washington State University, Pullman, WA \\ 99164, USA \\ ${ }^{2}$ Department of Horticulture, Washington State University, Pullman, WA 99164, USA \\ *Corresponding author, Phone: 509-335-8828; E-mail: sindhuja.sankaran@wsu.edu.
}

\section{Abstract}

9

Crop loss assessment after an event of hailstorm can be inaccurate, subjective, inconsistent, and time consuming with the conventional method. Low-altitude, high-resolution aerial imaging using an unmanned aerial vehicle can be utilized for rapid assessment of target crops in a large scale, which can potentially improve the evaluation procedure. The goal of this study was to evaluate the feasibility of rapid and accurate assessment of crop damage due to simulated hailstorms using aerial multispectral imaging. Field experiments were conducted during two seasons in two potato varieties (Russet Norkotah, Ranger Russet) with three levels of mechanical defoliation $(33 \%, 66 \%$, and $99 \%)$ at three growth stages (tuber initiation, early bulk, and late bulk). All defoliation treatments were compared to the non-treated control plots ( $0 \%$ defoliation). Aerial multispectral images were collected between 77 and 108 days after planting (0 to 60 days after damage). Vegetation indices such as green normalized difference vegetation index (GNDVI), normalized difference vegetation index, and soil-adjusted vegetation index were calculated from replicate plots of different treatments. Results from two seasons showed similar trends in GNDVI values, with maximum effect of hail damage observed in tuber initiation stages. The mean GNDVI value was significantly lower in crops with the severe damage (99\% 
24 defoliation) than others upon hail damage at the early bulk stage, with imaging after 10 days

25 after damage. The difference in GNDVI for crops with 33-66\% damage could be detected within

2610 days after damage, and crop regrowth after that time period removed the effects of defoliation.

27 The 99\% defoliation damage at the early bulk stage also affected the crop yield significantly.

28 Correlation analysis between vegetation indices and yield data indicated a strong relationship $(r$ $29=0.77-0.90)$ for damage at the early bulk stage than other stages.

31 Keywords: Crop loss; remote sensing; vegetation indices; UAV

\section{Introduction}

Thunderstorm, especially a hailstorm is unpredictable and can cause serious damage to property and agricultural crops (Wang et al., 2012). In U.S., hail-induced crop damage accounts to $10 \%$ of the weather-induced crop losses resulting in an economic loss of US\$ 914.6 million in 2014 (U.S. Department of Agriculture Risk Management Agency, USDA-RMA, 2015). As a risk management strategy, many farmers/growers purchase crop insurance to prevent severe

39 economic losses related to such unintended natural events. The extent of crop loss due to hail damage is usually assessed by third party adjusters according to loss parameters, such as the amount of crop defoliation, harvesting difficulty, and direct amount of produce loss (Peters et al.,

42 2000; Apan et al., 2005). The loss parameters are typically measured using a series of

43 representative sites from the affected area. Often times, such assessment can be time consuming, 44 labor-intensive, and subjective. Therefore, an alternative rapid, reliable (quantitative), efficient, 45 and cost-effective crop loss evaluation technique is critically needed and desired by the 46 agribusiness industry and growers. 
Remote sensing technology has been used as a tool to detect crop loss due to biotic and

48 abiotic stress, such as drought, disease, frost and fire in numbers of studies (Zhang and Kovacs

49 2012; Mulla, 2013). Remote sensing commonly utilizes different optical sensors such as

50 multispectral and hyperspectral imaging systems with various platforms such as satellites,

51 airplanes, and helicopters, to capture aerial images of target fields and derive various vegetation

52 indices for crop loss assessment (Mulla, 2013). The potential of using remote sensing to improve

53 the crop loss assessment for insurance purposes has been summarized in de Leeuw et al. (2014).

54 The benefits and limitations of using remote sensing technology in crop insurance were

55 evaluated, and the technology was recommended as a low-cost solution that could enhance the

56 conventional crop loss assessment method. Capellades et al. (2009) analyzed the potential of

57 using 'RapidEye' remote sensing system (Satellite Imaging Corporation, Tomball, TX) to

58 estimate hail damage on insured corn and soybean crops. A soil-adjusted vegetation index (SAVI)

59 was successfully used to classify crops into seven damage levels within each field. Zhao et al.

60 (2012) studied the feasibility of assessing hail damage in corn using a mini-satellite with

61 multispectral imaging system. Based on normalized difference vegetation index (NDVI) values,

62 a model was developed to estimate the hail damage level and post-hailstorm damaged acreage.

63 An overall accuracy of $86 \%$ in determining damage levels was reported in their study. Similarly,

64 Peters et al. (2000) used an aircraft carrying a four band sensing system (red, green, blue, and

65 near infrared) to evaluate the simulated hail damage on corn and soybean fields. The extracted

66 NDVI values from the aerial images showed strong relationship with the ground reference

67 spectroradiometer data $\left(R^{2}=0.88-0.93\right)$. Utilization of satellite and aircraft for aerial imaging for

68 crop assessment can be limited by low spatial and temporal resolution, and high cost to operation

69 that may not be suitable especially for small size farms. 
In the past few years, unmanned aerial vehicles (UAVs) are attracting the interest of

71 researchers and commercial sectors for high-throughput data collection in precision agriculture

72 and phenomics (Sankaran et al., 2015; Khot et al., 2016). Compared to satellite-based remote

73 sensing, UAV can collect images with higher spatial resolution (up to $\mathrm{cm}$ ) and higher temporal

74 frequency based on the imaging needs at lower costs. Therefore, UAV may be used for

75 acquisition of high-resolution data in insured fields to assess crop losses due to hail damage and

76 other causes. The overall goal of this study was to evaluate the feasibility of UAV-based imaging

77 to estimate potato crop loss caused by simulated hailstorms. The specific objectives were to

78 determine the feasibility of using UAV-based temporal and spatial image data to estimate

79 different levels of hail damage, compare the sensitivity of different vegetation indices in hail

80 damage estimation, and assess the relationship between vegetation indices and crop yield.

81

\section{2. Materials and methods}

$83 \quad 2.1$ Field plots and hail damage simulation

The study was conducted during two field seasons in 2014 and 2015 at the Washington

85 State University Research Station near Othello, WA. Two potato varieties of Russet Norkotah

86 strain TX 278 (Norkotah), an early to medium maturing variety and Ranger Russet (Ranger), a

87 late maturing variety were planted into a prepared potato field. The field was segmented into 18

88 crop rows ( $86 \mathrm{~cm}$ width) with both varieties planted at $25 \mathrm{~cm}$ apart and $20 \mathrm{~cm}$ deep (Rows 1-9

89 for Norkotah, Rows 10-18 for Ranger) as shown in Fig. 1. Each row was separated into 13

90 sections with $5 \mathrm{~m}$ in length, and three sections from adjacent rows were used as a plot for the hail

91 damage treatments. The field was center-pivot irrigated and managed according to standard

92 regional practices. 
Effect of hail damage on the potato was tested in three different growth stages, i.e. Tuber

94 Initiation (TI), Early Bulk (EB), and Late Bulk $(L B)$ in both varieties. The details on the

95 treatment time period are as shown in Table 1, with $T I$ treatment at about 45 days after planting

96 (DAP), $E B$ treatment at about 75 DAP, and $L B$ treatment at about 93 and 119 DAP in Norkotah

97 and Ranger variety, respectively. Three levels of hail damage (33\%, 66\% and 99\% defoliation)

98 were simulated and compared with the control (0\% defoliation, Fig. 2). Hail damage of 33\% and

$9966 \%$ treatments was induced by sweeping a solid-tined garden rake with 16 curved tines, $2.5 \mathrm{~cm}$

100 apart, through the canopy along each row of the treated plot. Severe defoliation (99\%) was

101 induced using a Stihl ${ }^{\circledR}$ FS130 R string trimmer (Stihl ${ }^{\circledR}$ Corporation, Virginia Beach, VA). The

102 extent of defoliation was assessed by measuring ground cover with a ground cover grid for the $T I$

103 stage treatments. The ground cover grid was $86 \mathrm{~cm}$ (one row wide) by $75 \mathrm{~cm}$ with 100 string-

104 bordered squares formed by ten equally spaced strings stretched tightly from the sides of the grid.

105 Following defoliation, the ground cover grid was held horizontally approximately $40 \mathrm{~cm}$ above

106 the ground and centered over the row. A skilled person looked down to the grid from $40 \mathrm{~cm}$

107 above the grid and then counted the number of grid squares with more than $50 \%$ foliage

108 coverage. The ground cover $(\%)$ was the percentage of the counted number (foliage area) to the

109 overall number of squares (100), according to which the defoliation (\%) was estimated. For

110 example, a $67 \%$ ground cover will represent $33 \%$ defoliation. The defoliation of the $E B$ and $L B$

111 treatments was assessed by visual comparison of the canopy with the control plot (0\%). The

112 defoliated plant parts were moved to the outside of the plots to allow for accurate visual

113 assessment of damage. The presence and absence of dead plants may affect the hail evaluation

114 using imaging, although we anticipate that the effect will be minimal based on our previous work

115 where we evaluated potato senescence rates using aerial imaging (Khot et al., 2016). Three 
different damage levels and control treatments were applied into twelve plots from each variety using a randomized complete block design (RCBD) method with three replicates.

Prior to tuber harvest, vines of Norkotah naturally senesced or were mechanically removed using a flail mower at $130 \mathrm{DAP}$ and Ranger vines were mowed at $150 \mathrm{DAP}$. Tubers were harvested from each plot using a custom-built one row harvester. Final yield was measured using a custom-built electronic potato sizer.

\subsection{Data collection}

An unmanned aerial vehicle was used to collect high-resolution multispectral images from the target plots. The UAV (OktoXL 6S12, HiSystems GmbH, Moormerland, Germany) platform was remotely controlled by a radio transmitter (MX20 Hott, Graupner, Stuttgart,

Germany) with control range of up to $4 \mathrm{~km}$. The platform has a maximum payload of $4 \mathrm{~kg}$ and can fly about 20 min with a 6500 mAh Lithium-ion polymer battery pack. A modified multispectral digital camera, NiteCanon ELPH110 (LDP LLC, Carlstadt, NJ, USA), where one of the visible bands was replaced with near infrared band was utilized in this study. In 2014, the camera bands were near infrared (NIR), green (G), and blue; while in 2015, the bands were red (R), G and NIR. The camera was mounted on to a gimbal system underneath the UAV that was capable of automatically adjusting the nick and roll shifts to the pre-set orientation during flight. A firmware was used to enable geo-referenced interval shooting to acquire images every $5 \mathrm{~s}$ during the flight with an image resolution of 16.1 megapixels $(4608 \times 3456)$, stored in an onboard SD card for further processing. A white reflectance reference panel was used for radiometric calibration to correct for natural sunlight variation. The image pixel values in each band were corrected based on correction factor estimated from white reference panel 
139 standardized to represent about $100 \%$ reflectance. The flight altitude was $100 \mathrm{~m}$ above ground

140 level. Table 1 summarizes the imaging period with respect to treatment, with time period

141 presented as days after damage (DAD). In 2014, imaging was performed at 60 DAD after TI

142 treatment in both varieties, 35 and 21 DAD after EB treatment in Norkotah and Ranger variety,

143 respectively, and 10 DAD after $L B$ treatment in Norkotah variety. In 2015, the imaging was

144 performed twice, at 32 and 52 DAD after $T I$ treatment in both varieties, about 2 and 22 DAD

145 after $E B$ treatment in both varieties, and 4 DAD after $L B$ treatment in Norkotah variety. In both

146 years, imaging after $L B$ treatment in Ranger variety was not performed as the plants were

147 naturally senescing. The imaging time period between 77 and 108 DAP was selected to achieve

148 the maximum variability of DAD with respect to treatment time in both varieties at different

149 growth phases, while avoiding environmental conditions such as rain events and windy

150 conditions $(>16 \mathrm{~km} / \mathrm{h})$.

151

152

2.3 Data processing and analysis

One of visible symptoms of crops subjected to hail damage is the substantial defoliation,

154 which is a key parameter used by field adjusters in crop loss assessment (Shields and Wyman,

155 1984). The defoliation may lead to the change of canopy size and affect the crops' ability to

156 effectively conduct photosynthesis, even cause crops to senesce prematurely depending on the

157 extent of damage. The changes in the crop canopy can be measured using different vegetation

158 indices indicative of overall crop health (de Leeuw et al., 2014), such as normalized difference

159 vegetation index (Rouse et al., 1974), green normalized difference vegetation index (GNDVI;

160 Gitelson et al., 1996) and soil-adjusted vegetation index (Huete, 1988; Qi et al., 1994). High-

161 resolution aerial imagery data were analyzed to extract NDVI, GNDVI or SAVI values from 
162 each plot under different treatments. Feature extraction algorithm was developed using Matlab ${ }^{\circledR}$

163 (ver. 2014a, The MathWorks, MA, USA) with the following key steps: (1) each image was

164 separated into the individual band images, (2) each band image was radiometrically calibrated

165 with white reflectance reference panel, (3) corrected band images were utilized to acquire NDVI,

166 GNDVI or SAVI images using Eq. 1-3, (4) background (soil) was removed using a threshold, (5)

167 individual plots were segmented from the processed images, and (6) mean NDVI, GNDVI and

168 SAVI values of each plot was calculated as image features.

169

170

171

$$
N D V I=\frac{N I R-R}{N I R+R}
$$

$$
G N D V I=\frac{N I R-G}{N I R+G}
$$

$$
S A V I=\frac{N I R-R}{N I R+R+L} *(1+L)
$$

172 where $N I R, R$ and $G$ are the pixel values (reflectance) of three bands in the images, respectively.

$173 L$ is the soil brightness correction factor. An $L$ value of 0.5 was used in this study, which

174 generally works well in different canopy conditions (Ray, 2010).

175

The sensitivity of the vegetation indices with respective to hail damage was quantified

176 using the slope of a linear relationship between specific vegetation index (NDVI, GNDVI, SAVI)

177 and the associated hail damage levels (0-99\%), which was calculated using the following

178 equation (Gitelson et al., 2002)

179

$$
M=\left|\frac{x 1-x 2}{x 1}\right| \times 100
$$

180 where $M$ is a slope of a linear relationship of indices at two consecutive points (damage levels),

181 and $x 1$ and $x 2$ are vegetation index values associated with the two damage levels. The higher

182 slope values indicate the higher sensitivity of the vegetation index to the hail damage. 
Statistical analysis (ANOVA) was performed to evaluate treatment effects on the

184

185

186

187

188

189

190

191

192

193

194

195

196

197

198

199

200

201

202

203

204

205

vegetation indices using SAS $^{\circledR}$ (ver. 9.2, SAS Institute, Cary, NC, USA). Least square mean difference was utilized to compare the treatment at $5 \%$ level of significance. The Pearson correlation coefficient $(r)$ between vegetation index values and yield data was determined as well.

The graphs were plotted using SigmaPlot ${ }^{\circledR}$ (ver. 11.0, Systat Software Inc., San Jose, CA, USA).

\section{Results and discussion}

3.1 GNDVI-based hail damage assessment

The mean GNDVI of three replicate treatments in each stage was calculated for both potato varieties. The treatment effects (0-99\% hail damage) with respect of imaging periods (DAD) at different potato growth stages are as shown in Figs. 3 and 4. In 2014 season, the image was acquired at 108 DAP resulting in 60, 21-35, and 10 DAD at $T I, E B$, and $L B$, respectively (Table 1). Fig. 3a shows that there was no significant difference in mean GNDVI values between the hail damage levels at $60 \mathrm{DAD}$ for treatments at $T I$ stage in both varieties. The reason for this observation was that potato crops damaged by hailstorm at early growth stages had recovered completely from damage. However, at $E B$ stages, severe damage (99\% defoliation) affected the crops significantly as determined using GNDVI in both varieties (Fig. 3b), which was significantly lower than that of the control and less damaged crops (33 and 66\%). These findings were in agreement with prior studies, which indicated that the potato plants were most susceptible to damage during tuber formation or flowering stages (Irigoyen et al., 2011). The 33\% and $66 \%$ damaged crops recovered from damage after 21-35 days and their GNDVI values were comparable to those of the control treatment (0\%). At $L B$ stage (Fig. 3c), the mean GNDVI of crops decreased significantly with increase in damage levels at 10 DAD imaging. Strong 
correlation between the mean GNDVI and the damage levels indicates that aerial imaging within 10 DAD could be useful in assessing the level of hail damage of crops under practical conditions. Fig. 4 shows the results of 2015 season data collected at 77 DAP and 97 DAP (Table 1). Similar GNDVI pattern was observed as found in 2014. For treatments at $T I$ stage in both varieties (Fig. 4a and 4c), the difference in mean GNDVI between the hail damaged levels was not significant, as observed at $32 \mathrm{DAD}$ or $52 \mathrm{DAD}$. This could be attributed to plant regrowth from the simulated hail damage in the $T I$ growth stage. Similar to 2014 results again, at $E B$ stage for both varieties (Fig. 4b and 4d), crops with severe damage (99\% defoliation) had significantly lower GNDVI values than those of control and lower damage (33\% and 66\%) treatments. Additionally, as observed in Fig. 4b, d, a decreasing GNDVI trend with respect to increase in damage levels could be observed from the images captured within 2 DAD for both varieties. However, after about 22 DAD, the difference in GNDVI values between control and lower damage levels (33-66\%) could not be noticed due the recovery of damaged crops (similar as 2014 results in Fig. 3b). Thus, results indicate that it is critical to take images as soon as possible after hail damage to distinguish the differences in damage levels unless the damage is significant (99\%). Similar GNDVI trend was observed at $L B$ stage (Fig. 4e), which was imaged at 4 DAD. The results reconfirm the findings from 2014 season, proposing imaging within 10 DAD to observe differences in hail damage levels.

\subsection{Sensitivity of vegetation indices}

Sensitivity analysis of three vegetation indices (NDVI, GNDVI, SAVI) was performed to determine their ability to assess hail damage. The computed slope values for three vegetation indices are summarized in Table 2. In general, SAVI slope values were higher than NDVI and 
229 GNDVI, indicating a higher sensitivity to hail damage level. Other studies have recommended 230 the use of SAVI in scenarios where crops do not completely cover the soil, due to possible 231 interference from the soil reflectance on the vegetation index values (Huete, 1988; Qi et al., 232 1994). However, further studies are needed to validate the results reported in this study. Overall, 233 even though SAVI showed higher sensitivity, all three indices could be used for assessing the 234 damage levels as similar trends were observed with different hail damage levels.

The effect of hail damage on crop loss was analyzed by comparing the mean yield of crops with different treatments, which is shown in Fig. 5. In general, there was no significant

239 difference in mean crop yields of control groups and those with 33-66\% damage treatment at 5\%

240 level of significance in both varieties and years. However, severe damage (99\%) at $E B$ stage

241 caused significantly lower yield than that of crops with less damage (33 and 66\%) and control in 242 both varieties and years. Further ANOVA analysis also showed that the interaction effect of 243 treatment time (growth stage) and damage level was not significant $(p=0.4636)$, while growth 244 stages affected the yield significantly $(p=0.0011)$ with the crop yield at $E B$ stage significantly 245 lower than that at $T I$ and $L B$ stages. Results are in agreement with the findings as understood 246 using GNDVI data, which were always significantly lower than control groups (Fig. 3 and Fig. 247 4). Other studies have found similar results (Apan et al., 2005; Irigoyen et al., 2011; Stieha and 248 Poveda, 2015). The correlation between the vegetation indices at different growth stages with that of 250 yield was evaluated and Pearson correlation coefficients are summarized in Table 3 . The 251 vegetation indices showed a good correlation $(r>0.77$; $p$-value $<0.05)$ with crop yield in the $E B$ 
252 stage. For crops treated in $T I$ stage, a weak correlation between yield and vegetation index values

253 were observed ( $r=0.03-0.59)$, which could be due to minor differences in both vegetation index

254 values and yield between treatments. For crops treated in $L B$ stage, the $r$ between vegetation

255 indices and yield ranged from 0.74 to 0.79 . These values were lower than those in $E B$ stage,

256 although significant. It was interesting to note that although the GNDVI values at 20-35 DAD

257 could not be utilized to differentiate between control and mild-moderate hail damage symptoms,

258 there was a good correlation between these values and yield data in both varieties. This indicates

259 the potential of UAV-based sensing for other applications in agriculture such as yield prediction,

260 which needs to be further investigated.

261

262

263

264

265

266

267

268

269

270

271 with crop yield. With respect to different imaging periods after the hail damage treatment (0-60

272 days), it could be recommended that differences in hail damage effects (defoliation) can only be

273 observed when imaged within 10 days after damage. Beyond this time period, the plant regrowth 
274 can mask the hail damage effects. Overall, UAV-based imaging method provides a potential

275 alternative method for hail damage assessment in agriculture.

276

277 Acknowledgements

278 The author would like to express their gratitude to Dr. Lav R. Khot, Center for Precision and

279 Automated Agricultural Systems, Washington State University for his assistance in aerial data

280 collection. The authors would also like to thank National Crop Insurance Services and Dr. Mark

281 Zarnstorff, NCIS Director Agricultural Research \& Technology, for partial funding of this

282 project and the Washington State Potato Commission for partial funding of a graduate student

283 associated with this research. This activity was also funded, in part, with USDA National

284 Institute for Food and Agriculture, Hatch Project, 1002864 (WNP00821).

285

286

References

287 Apan, A., O. Chandler, F. R. Young, and T. N. Maraseni. 2005. Opportunities and limitations of remote sensing for crop loss (hail damage) assessment in the insurance industry. In Proceedings of the 2005 Spatial Sciences Institute Biennial Conference 2005: Spatial Intelligence, Innovation and Praxis (SSC2005). Spatial Sciences Institute.

Capellades, M. A., S. Reigber, and M. Kunze. 2009. Storm damage assessment support service in the US Corn Belt using RapidEye satellite imagery. In SPIE Europe Remote Sensing. International Society for Optics and Photonics.

294 de Leeuw, J., A. Vrieling, A. Shee, C. Atzberger, K. M. Hadgu, C. M. Biradar, H. Keah, and C. 295 Turvey. 2014. The potential and uptake of remote sensing in insurance: a review. Remote 296 Sensing 6(11):10888-10912. 
297 Gitelson, A. A., Y. J. Kaufman, and M. N. Merzlyak. 1996. Use of a green channel in remote

298

299

300

301

302

303

304

305

306

307

308

309

310 sensing of global vegetation from EOS-MODIS. Remote Sensing of Environment 58(3):289-298.

Gitelson, A. A., Y. J. Kaufman, R. Stark, and D. Rundquist. 2002. Novel algorithms for remote estimation of vegetation fraction. Remote Sensing of Environment 80(1):76-87.

Huete, A. R. 1988. A soil-adjusted vegetation index (SAVI). Remote Sensing of Environment 25(3):295-309.

Irigoyen, I., I. Domeño, and J. Muro. 2011. Effect of defoliation by simulated hail damage on yield of potato cultivars with different maturity performed in Spain. American Journal of Potato Research 88(1):82-90.

Khot, L.R., Sankaran, S., Carter, A.H., Johnson, D.A., and Cummings, T.F. 2016. UAS imagingbased decision tools for arid winter wheat and irrigated potato production management. International Journal of Remote Sensing 37(s): 125-137.

Mulla, D. J. (2013). Twenty five years of remote sensing in precision agriculture: Key advances and remaining knowledge gaps. Biosystems Engineering, 114(4), 358-371.

Peters, A. J., S. C. Griffin, A. Viña, and L. Ji. 2000. Use of remotely sensed data for assessing crop hail damage. Photogrammetric Engineering and Remote Sensing 66(11):1349-1356.

Qi, J., A. Chehbouni, A. Huete, Y. Kerr, and S. Sorooshian. 1994. A modified soil adjusted vegetation index. Remote Sensing of Environment 48(2):119-126.

Ray, T.W. 2010. A FAQ on vegetation in remote sensing. Available at: www.yale.edu/ceo/Documentation/rsvegfaq.html, Accessed on: December 1, 2015.

Rouse, J. W., R. Haas, J. Schell, and D. Deering. 1974. Monitoring vegetation systems in the Great Plains with ERTS. NASA special publication 351:309. 
Sankaran, S., L. R. Khot, C. Z. Espinoza, S. Jarolmasjed, V. R. Sathuvalli, G. J. Vandemark, P. N. Miklas, A. H. Carter, M. O. Pumphrey, N. R. Knowles, and M. J. Pavek. 2015. Lowaltitude, high-resolution aerial imaging systems for row and field crop phenotyping: A review. European Journal of Agronomy 70:112-123.

Shields, E., and J. Wyman. 1984. Effect of defoliation at specific growth stages on potato yields. Journal of Economic Entomology 77(5):1194-1199.

Stieha, C., and K. Poveda. 2015. Tolerance responses to herbivory: implications for future management strategies in potato. Annals of Applied Biology 166(2):208-217.

U.S. Department of Agriculture Risk Management Agency (USDA-RMA). 2015. RMA Cause of Loss Historical Data Files. Available at: www.rma.usda.gov/data/cause.html, Accessed on: December 1, 2015.

Wang, E., B. L. Bertis, R. W. Jimmy, and Y. Yu. 2012. Simulation of hail effects on crop yield losses for corn-belt states in USA. Transactions of the Chinese Society of Agricultural Engineering 28(21):177-185.

Zhang, C., and J. M. Kovacs. (2012). The application of small unmanned aerial systems for precision agriculture: a review. Precision Agriculture, 13(6), 693-712.

Zhao, J., D. Zhang, J. Luo, S. Huang, Y. Dong, and W. Huang. 2012. Detection and mapping of hail damage to corn using domestic remotely sensed data in China. Australian Journal of Crop Science 6(1):101-108. 
Table 1. Simulated potato hail damage treatment and aerial data collection periods presented as days after planting (DAP) and days after damage (DAD). Tuber Initiation, Early Bulk, and Late Bulk growth stages are indicated as $T I, E B$, and $L B$, respectively.

\begin{tabular}{|c|c|c|c|c|c|c|}
\hline \multirow[b]{2}{*}{ Year } & \multirow[b]{2}{*}{ Variety } & \multicolumn{2}{|c|}{ Treatment time } & \multicolumn{3}{|c|}{ Imaging time (DAD, days) } \\
\hline & & $\begin{array}{c}\text { Growth } \\
\text { stage }\end{array}$ & $\begin{array}{l}\text { DAP } \\
\text { (days) }\end{array}$ & $77 *$ & $97 *$ & $108^{*}$ \\
\hline \multirow{6}{*}{2014} & \multirow{3}{*}{ Norkotah } & $T I$ & 48 & -- & -- & 60 \\
\hline & & $E B$ & 73 & -- & -- & 35 \\
\hline & & $L B$ & 98 & -- & -- & 10 \\
\hline & \multirow{3}{*}{ Ranger } & $T I$ & 48 & -- & -- & 60 \\
\hline & & $E B$ & 87 & -- & -- & 21 \\
\hline & & $L B$ & 123 & -- & - & -- \\
\hline \multirow{6}{*}{2015} & \multirow{3}{*}{ Norkotah } & $T I$ & 45 & 32 & 52 & -- \\
\hline & & $E B$ & 75 & 2 & 22 & -- \\
\hline & & $L B$ & 93 & -- & 4 & -- \\
\hline & \multirow{3}{*}{ Ranger } & $T I$ & 45 & 32 & 52 & -- \\
\hline & & $E B$ & 77 & 0 & 20 & -- \\
\hline & & $L B$ & 119 & -- & -- & -- \\
\hline
\end{tabular}

*indicate aerial data collection period as DAP.

Table 2. Green normalized difference vegetation index (GNDVI), normalized difference vegetation index (NDVI) and soil-adjusted vegetation index (SAVI) sensitivity values to crop damage levels at different growth stages in 2015. Early Bulk and Late Bulk growth stages are indicated as $E B$ and $L B$, respectively.

\begin{tabular}{ccccccccccc}
\hline Imaging & & \multicolumn{10}{c}{ Slope $(\%)$} \\
\cline { 3 - 11 } $\begin{array}{c}\text { time } \\
\text { (Days } \\
\text { after }\end{array}$ & Damage & levels & \multicolumn{1}{c}{ Ranger- $E B$} & \multicolumn{1}{c}{ Norkotah- $E B$} & \multicolumn{3}{c}{ Norkotah- $L B$} \\
Planting) & $(\%)$ & GN & NDV & SAV & GND & NDV & SAV & GND & NDV & SAV \\
& & DVI & I & I & VI & I & I & VI & I & I \\
\hline \multirow{3}{*}{77} & $0-33$ & 16.6 & 20.1 & 46.0 & 2.5 & 4.3 & 2.7 & -- & -- & -- \\
& $33-66$ & 24.3 & 32.9 & 62.9 & 16.1 & 26.3 & 49.3 & -- & -- & -- \\
& $66-99$ & 15.9 & 45.8 & 68.5 & 49.3 & 78.1 & 75.2 & -- & -- & -- \\
\hline \multirow{3}{*}{97} & $0-33$ & 0.6 & 1.6 & 2.0 & 5.5 & 4.7 & 5.9 & 23.3 & 36.1 & 45.3 \\
& $33-66$ & 3.6 & 10.3 & 12.5 & 8.0 & 14.1 & 17.5 & 47.0 & 55.2 & 70.7 \\
& $66-99$ & 82.1 & 86.4 & 94.3 & 75.4 & 82.2 & 88.7 & 20.6 & 54.5 & 80.4 \\
\hline
\end{tabular}


350 Table 3. Pearson correlation coefficients $(r)$ between potato yield and the developed vegetation 351 indices acquired from different hail damage treatments in different growth stages. Tuber

352 Initiation, Early Bulk, and Late Bulk growth stages are indicated as $T I, E B$, and LB, respectively.

\begin{tabular}{|c|c|c|c|c|c|c|c|c|c|}
\hline \multirow{3}{*}{ Variety } & \multirow{3}{*}{$\begin{array}{c}\text { Imaging } \\
\text { year } \\
\text { (Days } \\
\text { after } \\
\text { Planting) }\end{array}$} & \multirow{2}{*}{$\begin{array}{c}\text { Treatme } \\
\text { nt }\end{array}$} & \multirow{2}{*}{ Imaging } & \multicolumn{6}{|c|}{ Pearson correlation coefficients $(r), \mathrm{n}=12$} \\
\hline & & & & \multicolumn{2}{|c|}{ GNDVI } & \multicolumn{2}{|c|}{ NDVI } & \multicolumn{2}{|c|}{ SAVI } \\
\hline & & Stages & & $r$ & $p$ & $r$ & $p$ & $r$ & $p$ \\
\hline \multirow{8}{*}{ Norkotah } & \multirow{3}{*}{$\begin{array}{l}2014 \\
(108)\end{array}$} & $T I$ & 60 & 0.44 & 0.23 & -- & -- & -- & -- \\
\hline & & $E B$ & 35 & 0.77 & 0.00 & -- & -- & -- & -- \\
\hline & & $L B$ & 10 & 0.74 & 0.01 & -- & -- & -- & -- \\
\hline & \multirow{2}{*}{$2015(77)$} & $T I$ & 32 & 0.43 & 0.16 & 0.47 & 0.12 & 0.59 & 0.04 \\
\hline & & $E B$ & 2 & 0.87 & 0.00 & 0.88 & 0.00 & 0.82 & 0.00 \\
\hline & \multirow{3}{*}{2015 (97) } & $T I$ & 52 & 0.03 & 0.92 & 0.22 & 0.49 & 0.22 & 0.49 \\
\hline & & $E B$ & 22 & 0.82 & 0.00 & 0.82 & 0.00 & 0.81 & 0.00 \\
\hline & & $L B$ & 4 & 0.79 & 0.00 & 0.76 & 0.00 & 0.74 & 0.01 \\
\hline \multirow{6}{*}{ Ranger } & \multirow{2}{*}{$\begin{array}{l}2014 \\
(108) \\
\end{array}$} & $T I$ & 60 & 0.49 & 0.18 & -- & -- & -- & -- \\
\hline & & $E B$ & 21 & $\mathbf{0 . 8 3}$ & 0.00 & -- & -- & -- & -- \\
\hline & \multirow{2}{*}{2015 (77) } & $T I$ & 32 & 0.39 & 0.20 & 0.33 & 0.29 & 0.39 & 0.20 \\
\hline & & $E B$ & 0 & 0.82 & 0.00 & 0.90 & 0.00 & 0.83 & 0.00 \\
\hline & \multirow{2}{*}{2015 (97) } & $T I$ & 52 & 0.10 & 0.75 & 0.22 & 0.49 & 0.22 & 0.50 \\
\hline & & $E B$ & 20 & 0.88 & 0.00 & 0.90 & 0.00 & 0.90 & 0.00 \\
\hline
\end{tabular}


362

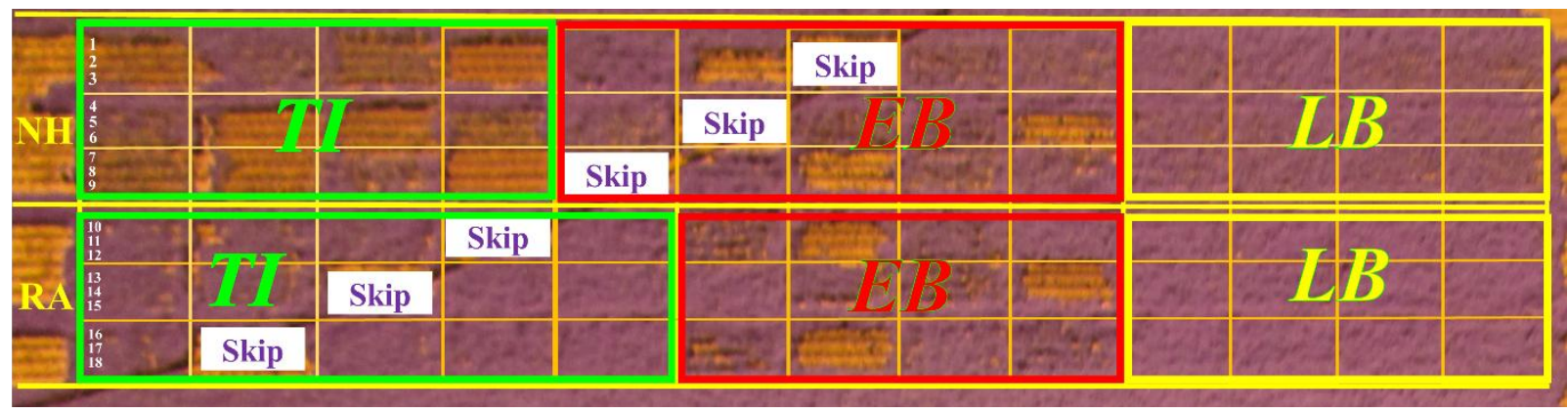

Fig. 1. False color image (R, G, NIR) taken at 95 days after planting (DAP) in 2015 shows the experimental plots. NH and RA refer to Norkotah and Ranger varieties, respectively. Potato crops were treated at three growth stages, tuber initiation $(T I)$, early bulk $(E B)$ and late bulk $(L B)$ respectively. Three replicate plots with four defoliation levels $(0,33,66,99 \%)$ were applied to the crops in each growth stage using randomized complete block design. "Skip" indicates an unplanted gap left for the center-pivot tire track.

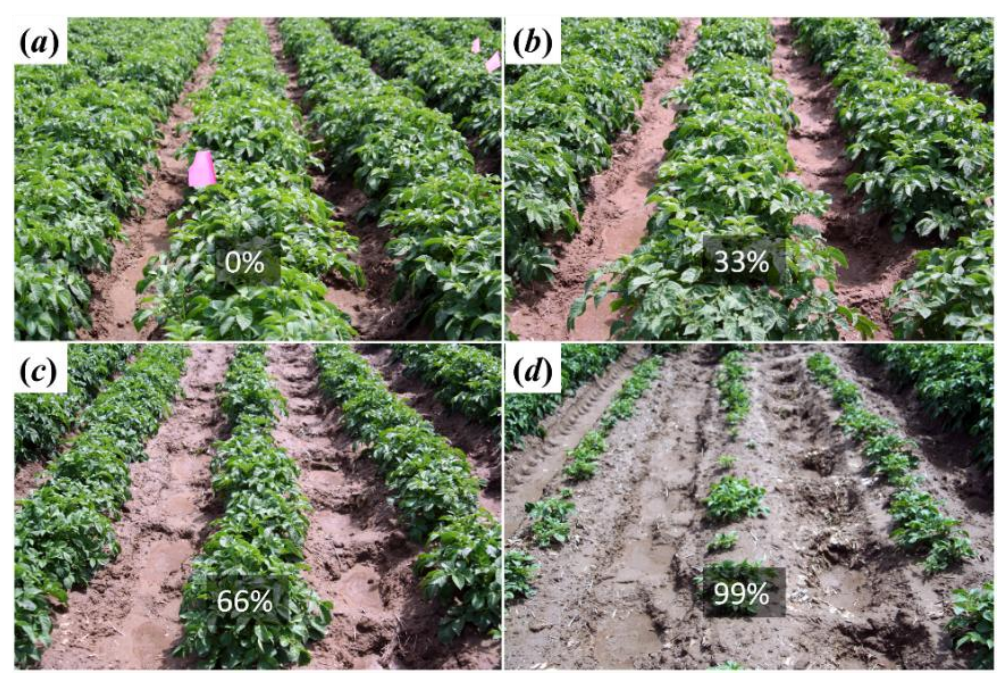

Fig. 2. Picture of Russet Norkotah field plots at 11 days after defoliation (simulated hail) at Tuber Initiation stages with plots representing (a) 0\% (Control), (b) 33\%, (c) 66\%, and (d) $99 \%$ defoliation levels. 

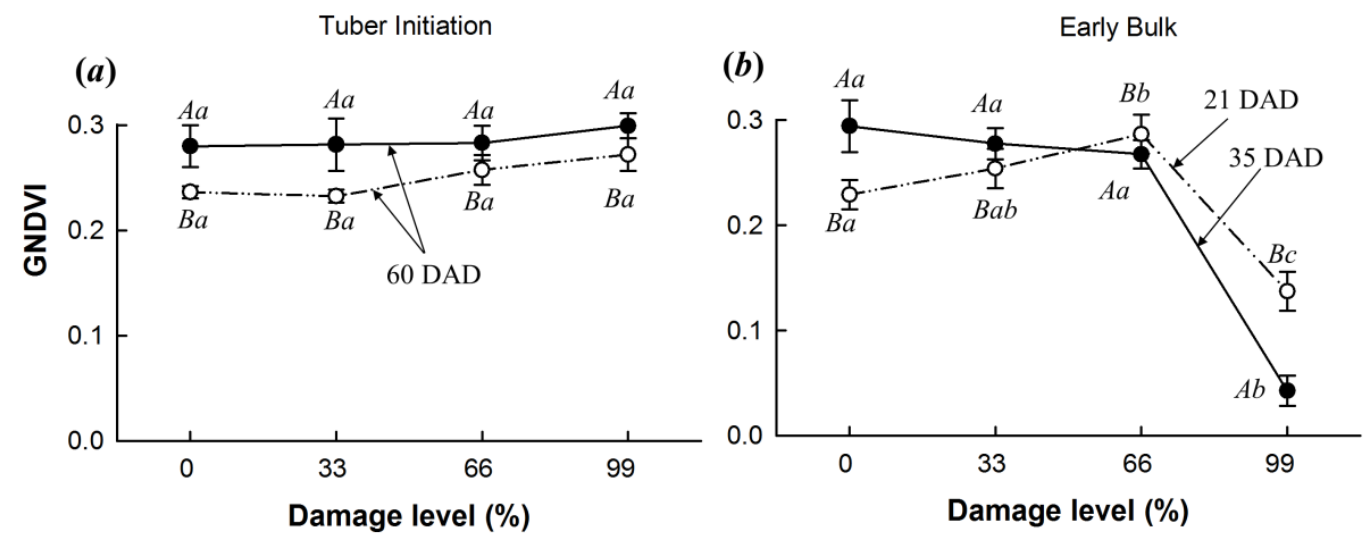

(c)

Late Bulk
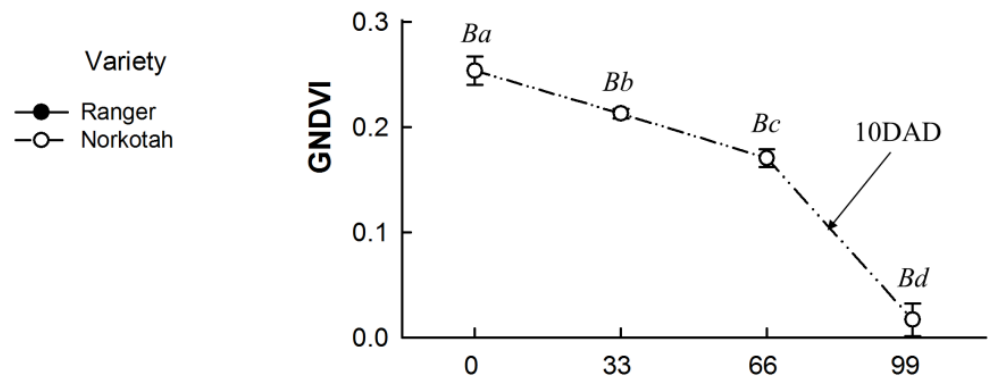

Damage level (\%)

Fig. 3. Green normalized vegetation index (GNDVI)-based hail damage assessment of two potato varieties with four simulated damage levels at (a) Tuber Initiation, (b) Early Bulk, and (c) Late Bulk growth stages in 2014. Imaging time period is represented as days after damage (DAD). The statistical analysis was performed to compare the mean GNDVI values in each

372 variety and at each stage, respectively. The capital letters refer same variety data, and the small 373 letters indicate the significant differences in average GNDVI among different treatments at 5\% 374 level of significance. 

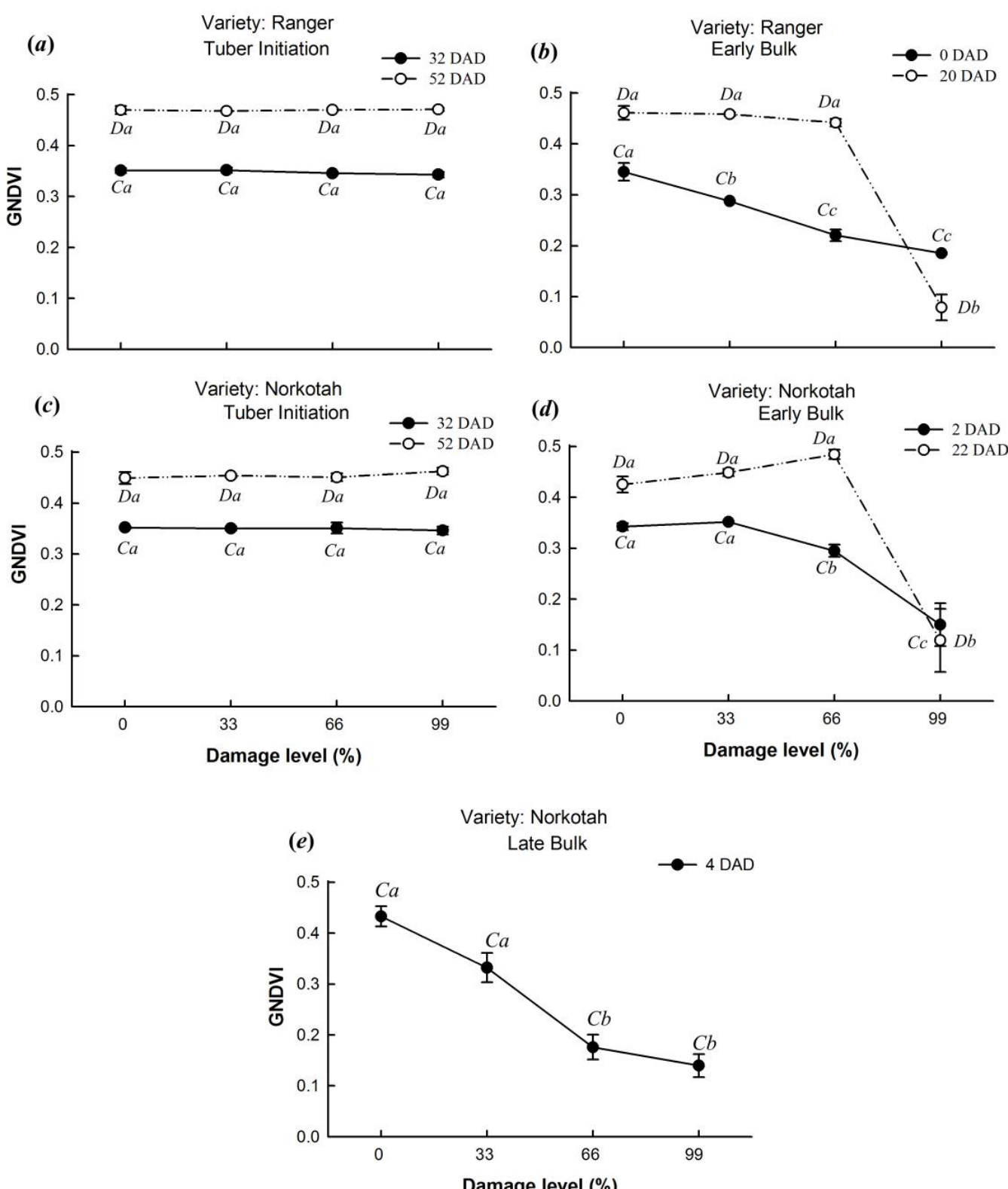

Damage level $(\%)$

379 Fig. 4. Green normalized vegetation index (GNDVI)-based hail damage assessment of two potato varieties with four simulated damage levels at three growth stages in 2015. Ranger was evaluated at (a) Tuber Initiation and (b) Early Bulk stages, while Norkotah was evaluated at (c) Tuber Initiation, (d) Early Bulk, and (e) Late Bulk stages. Imaging time period is represented as days after damage (DAD). The capital letters refer to same time period data, and the small letters indicate the significant differences in average GNDVI among different treatments at $5 \%$ level of significance. 

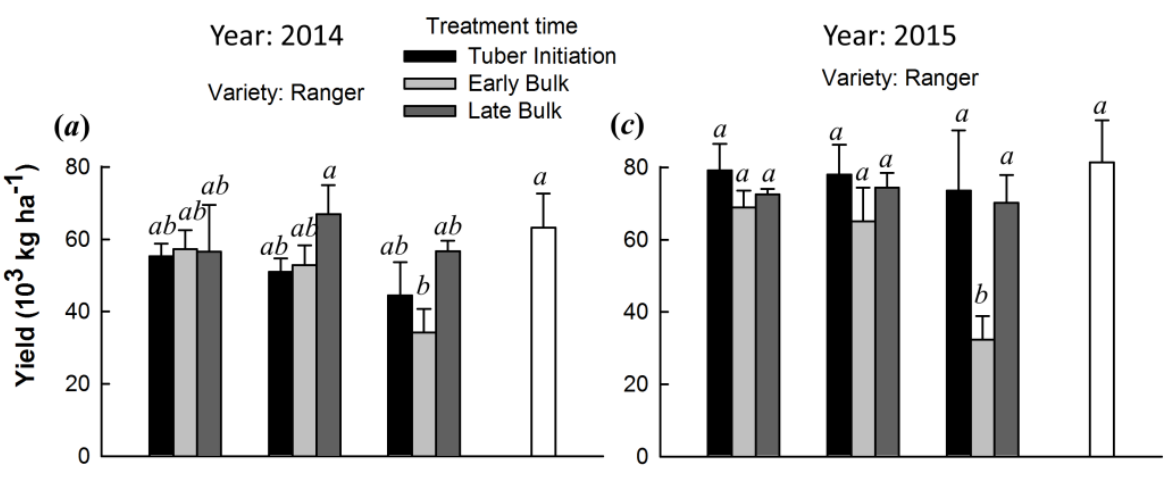

(b)

Variety: Norkotah
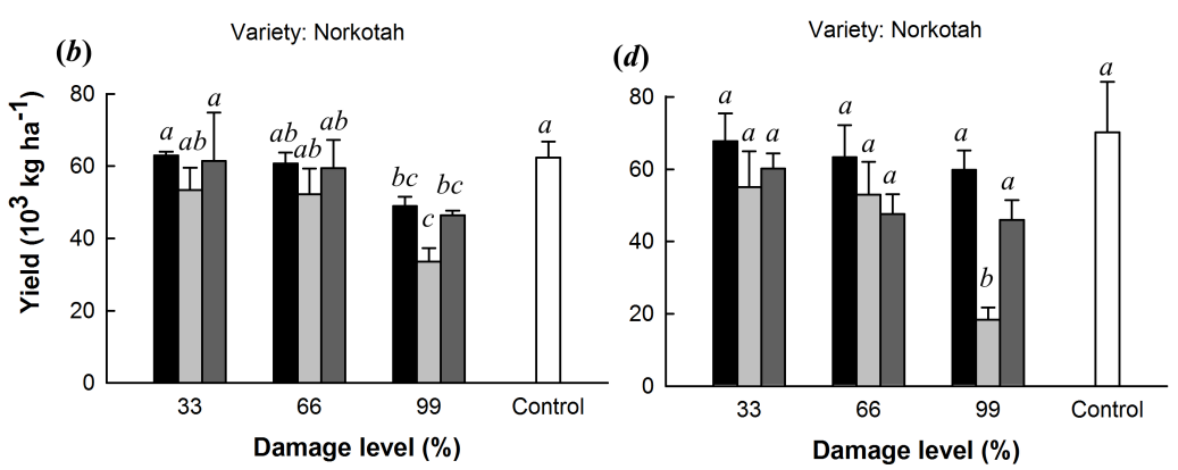

Fig. 5. Mean yield of two potato varieties with four simulated damage levels at three growth stages in two seasons: (a) Ranger in 2014; (b) Norkotah in 2014; (c) Ranger in 2015 and Norkotah in 2015. The statistical analysis was performed to compare the yield data at each variety-growth stage hail treatment combinations separately. Different letters indicated significant difference in the mean values at $5 \%$ level of significance. 